\title{
The Role of Sri Lankan Stock Market in the Asian Region
}

\author{
D. Kuruppuarachchi \\ University of Sri Jayewardenepura, Sri Lanka
}

\begin{abstract}
This paper investigates the interaction of the Sri Lankan stock market with other Asian stock markets in terms of cointegration, contemporaneous correlations, information spillovers, and impulse responses. The study consider India, China, Pakistan, Singapore, Malaysia, Hong Kong, Korea, and Japan as neighboring stock markets to the Sri Lankan market. And it use daily data of leading stock indices for each country from 01st January 2000 to 31st December 2012. Findings reveal that the Sri Lankan stock market is cointegrated with the Korean stock market but not with others. Contemporaneous correlations are significant between Sri Lanka and other Asian countries such as India, Singapore, Malaysia, Hong Kong, Korea, and Japan. Pakistan, Malaysian, and Korean stock markets Granger cause in mean to the Sri Lankan stock market while India and Korea Granger cause in variance. Extreme downside risks in Chinese stock market also Granger causes the Sri Lankan stock market. Impulse response analysis provides evidence for the following day's impact on the Sri Lankan stock market due a current shock on other Asian stock markets. Findings of this paper provide insightful information to both policy makers and investors in order to understand the behavior of Sri Lankan stock market.
\end{abstract}

\section{Keywords}

Asian Stock Markets, Granger Causality, Impulse Response, Information Spillover, Sri Lankan Stock Market, Stock Market Interactions 


\section{Introduction}

This paper investigates how the Sri Lankan stock market interacts with other Asian stock markets. Specifically, it examines the following research questions; 1) does the Sri Lankan stock market integrate with other Asian stock markets? 2) are there information spillovers from other Asian markets to the Sri Lankan stock market? 3) Is the information in the Sri Lankan stock market spilled over to other Asian stock markets? Answering these questions permits us to identify whether the Sri Lankan stock market is alone in the Asian region or not. For this investigation, apart from the Sri Lankan stock market, eight Asian stock markets namely, India, China, Pakistan, Singapore, Malaysia, Hong Kong, Korea, and Japan were selected. It is important to investigate market linkages between Sri Lanka and other regional markets as the Sri Lankan capital market has the potential of being influenced by above mentioned regional markets due to various trading partnerships. Investors may have interests on the behavior of the Sri Lankan stock markets against the fluctuations in parent markets where such partnerships are established. On the other hand, if the interaction between the Sri Lankan stock market and the other stock markets is weak, then the investors have a potential of diversifying their risks by investing in Sri Lankan stocks as the Sri Lankan stock market has been opened to foreign investors since 1989. In fact, this study contributes to the existing literature examining the level of internationalization of the Sri Lankan stock exchange to the Asian region.

Sri Lankan stock market is operated by the Colombo Stock Exchange (CSE) which is the only share market in the country. The CSE is responsible for providing a transparent and regulated environment where companies and investors can come together. The CSE was one of the first exchanges in the region to have in place a depository for listed securities with the implementation of its clearing and settlement house. In 1991, the CSE installed an automated electronic clearing and settlement systemCentral Depository System, and in 1997, the CSE introduced its Automated Trading System (ATS) which enhanced the transparency and efficiency of the securities market in Sri Lanka. The CSE was admitted to the World Federation of Exchanges (WFE) in 1998, becoming its first South Asian member with the recognition of the technology, systems and regulation. It was also a founding member of the South Asian Federation of Exchanges 
(SAFE) in 2000. The CSE also partnered with S\&P Indices to jointly develop the S\&P Sri Lanka 20 Index (S\&P SL 20) launched in June 2012. By the end of 2012, the equity turnover of the CSE was 200,467.8 million Sri Lankan rupees where 64 percent of this value is due to the local investments while remaining 36percent is due to the foreign investments. During this time frame, the number of listed companies in the CSE was 287 (CSE, 2014).

Previous attempts for investigating the interaction between the Sri Lankan and other regional markets are limited. Elyasiani, Perera, and Puri (1998) investigate the interdependence and dynamic linkages between the capital market of Sri Lanka and the markets of its major trading partners such as Taiwan, Singapore, Japan, South Korea, Hong Kong, India, and the US during 1989 to 1994. They conclude that there is no significant interdependence between the Sri Lankan market and the equity markets of the US and the Asian markets by employing VAR methodology. In contrast, P. Narayan, Smyth, and Nandha (2004) use an ADRL cointegrating framework on daily data from 1995 to 2001 and conclude that, in the long run, stock prices in Bangladesh, India and Sri Lanka Granger-cause stock prices in Pakistan. Moreover, in the short run, there is unidirectional Granger causality running from stock prices in Pakistan to India, stock prices in Sri Lanka to India and from stock prices in Pakistan to Sri Lanka. De Gooijer and Sivarajasingham (2008) also investigate the interactions between the Sri Lankan market with ten other leading stock markets (six industrialized markets and four emerging markets of South-East Asia) during 1987 to 2006 and found that no significant long-term causal linkages between Sri Lanka and the other countries. They incorporate both parametric and nonparametric Granger causality approaches in their study. Therefore, existing literature evidences for the interaction between Sri Lankan and other stock market are mixed. Since the study incorporate more recent data from year 2000 to 2012, which includes the global financial crisis period in 2008 , results of this study significantly contributes to extend this literature further.

In generall, interactions between Asian emerging stock markets has been growing attention in recent research. Improved flow of capital across national borders, reduction of transaction costs, increase in the flow of 
information, interests in identifying market leaders and followers, and diversification opportunities across less correlated markets are the main reasons for the increasing interest on emerging market interactions ( $\mathrm{P}$. Narayan et al., 2004). If markets are integrated, an unanticipated event in one market may influence not only on its own returns and volatility but also other markets' returns and volatility. Specifically, analyzing volatility and its spollovers is important because volatility indicates the risk of assets. The extent of the global linkage of emerging markets improves access to the international capital markets. Strong global linkage reduces the insulation of the emerging stock markets from external shocks, hence limiting the scope for independent monetary policy (Li \& Majerowska, 2008). Although financial market integration has been extensively studied for the developed markets and the research on the linkages among emerging markets in Asian region is limited. Moreover, the limited literature on these emerging markets is either mainly carried out by conventional methods, such as co-integration analysis, Granger causality tests with vector autoregressive models (VAR), volatility spillover analysis using multivariate GARCH models, and impulse response functions. A few examples can be cited such as Elyasiani et al. (1998), P. Narayan et al. (2004), Worthington and Higgs (2004), Yang, Hsiao, Li, and Wang (2006), and Joshi (2011). Moreover, the predictability of Asian market stock returns using the U.S. stock market bears and returns is investigated recently in S. Narayan (2015).

This paper contributes to the meagre published literature on integrations and interactions between the Sri Lankan and other Asian markets. It extends the methodology of testing the Granger causality between these markets by employing Hong's tests of causality in mean, variance, and value-at-risk (Hong, 2001; Hong, Liu, \& Wang, 2009). Granger causality in mean helps us to identify how the fluctuations of returns of one market causes fluctuations of the returns of another markets (i.e. information spillover in levels) while the causality in variance explains the volatility spillover from one market to another. Volatility spillover helps us to identify the transmission of market risks. Moreover, causality in valueat-risk assist us to identify the transmission of extreme risks from one market to another market. An extreme risk occurs due to an unusual movement in levels of prices. This study considers both downside and upside value-at-risks unlike previous studies where only the downside 
value-at-risk has considered. Because, an extreme rise in one market may also spillover information on another market due to investors' speculations. Furthermore, it investigates the potential impact to (from) the Sri Lankan stock market from (to) other Asian markets using the generalized impulse response functions introduced by Pesaran and Shin (1998).

The results indicate that, Sri Lankan stock market is not cointegrated with other Asian markets except with the Korean markets. Also, the Sri Lankan stock market contemporaneously correlates with stock markets in India, Singapore, Malaysia, Hong Kong, Korea, and Japan. Pakistanian, Malaysian, and Korean markets Granger cause the Sri Lankan market in means while Indian and Korean markets Granger cause in variance. Furthermore, extreme downside value-at-risk in Chinese stock market Granger causes the Sri Lankan market, but the causalities from upside market risks are not virtually significant. Remainder of the paper is organized as follows. Section two demonstrates the econometric methodology employed in this study. Section three presents data and results of the paper while section four concludes.

\section{Econometric Methods}

This paper addresses three issues corresponding to market-to-market interactions namely, market integration, information spillover, and response to shock from one market to another market. Additionally, it also analyzes contemporaneous correlations between stock market returns. Market integration is investigated using the conventional cointegration approach while the information spillover effect is investigated using Granger causality approach. Here, the author employs Hong (2001) methodology to test the Granger causality in mean and variance while Hong et al. (2009) approach to test the Granger causality in value-at-risk. The main reason for using these novel approaches opposed to conventional VAR and MVGARCH methods is that the ability of Hong's methodology to test Granger causality by using a series of lags (typically beyond VAR and MVGARCH specifications) with a high level of importance assigned on nearby lags. Finally, it investigate the potential impacts of shocks on other Asian markets to the Sri Lankan stock market and contrariwise using generalized impulse response functions developed by Pesaran and Shin (1998). 


\section{Cointegration Analysis}

Engle and Granger (1987) define a $N$ dimensional time series variable $X$, to be cointegrated of orders $d$ and $b(\mathrm{CI}(d, b))$ if it satisfies two conditions: (i) each component of $X$, when considered individually, is integrated of order zero after differencing $d$ times; and (ii) there exists at least one (and possibly $r$ ) "cointegrating vectors" $\gamma_{i}$ such that the linear combination $\gamma_{i}^{\prime} X$, is integrated of order zero after differencing $d-b$ times. When $d=b=$ $1^{1}$, this study defines cointegrating relationship between Sri Lankan stock market index, $X_{1}$ and another country's market index, $X_{2}$ as follows (i.e. $X=$ $\left.\left[X_{1}, X_{2}\right]\right)$.

$$
X_{1 t}=\alpha_{1}+\alpha_{2} X_{2 t}+\varepsilon_{t}
$$

When $X_{1} \sim I(1), X_{2} \sim I(1)$ and if $X_{1}$ and $X_{2}$ are cointegrated, then $\varepsilon_{t} \sim I(0)$ with a zero mean (Engle $\&$ Granger, 1987). Moreover, Phillips and Ouliaris (1990) provide asymptotic critical values to test the residual series of equation (1) for the unit root i.e., $H_{0}: \varepsilon_{t} \sim I(1)$. Eventually, $H_{0}: X_{1}$ and $X_{2}$ are not cointegrated vs. $H_{1}: X_{1}$ and $X_{2}$ are cointegrated were tested.

\section{Granger Causality Tests}

Methods such as the autoregressive model by Sims (1972) and the crosscorrelation approach by Haugh (1976), have been used in the literature to test Granger causality in mean. Cheung and Ng (1996) extended Haugh's (1976) approach to test the Granger causality in variance. Hong (2001) extended the Cheung and $\mathrm{Ng}$ (1996) approach by relaxing the constant weight assumption on previous lags and proposed a method to test both causality in mean and variance under conditional heteroscedasticity. He used the weighted sum of the cross-correlations method, which assigns larger weights on nearer lags compared with distant lags. Hong et al. (2009) extended this approach to test a new type of Granger causality, namely, causality in extreme downside risk in markets.

\footnotetext{
${ }^{1}$ This assumes that market index values are unit root processes. Using log of stock index values, the author tests all index values for unit roots using the augmented Dickey-Fuller unit root test and Phillips-Perron test. Results are not presented here to conserve the space and available upon request.
} 
Let $R_{i}(t)$ and $R_{j}(t)$ be the returns of market indices $i$ and $j$, respectively. Also, let $\Phi_{i}(t-1)$ and $\Phi_{j}(t-1)$ be the information sets corresponding to $R_{i}(t)$ and $R_{j}(t)$ at time $t-1$, respectively, and $\Phi(t-$ $1)=\left\{\Phi_{i}(t-1), \Phi_{j}(t-1)\right\}$. As defined in C. W. J. Granger (1980), the causality in mean of $R_{j}(t)$ on $R_{i}(t)$ with respect to $\Phi(t-1)$ is tested by testing the null hypothesis of no causality-in-mean from market sector $j$ to market sector $i$ in equation (2).

$$
E\left[R_{i}(t) \mid \Phi_{i}(t-1)\right]=E\left[R_{i}(t) \mid \Phi(t-1)\right]
$$

Using cantered standardized residuals, $\hat{u}_{t}=\hat{\varepsilon}_{1 t} / \hat{h}_{1 t}^{1 / 2}-1$, and $\hat{v}_{t}=$ $\hat{\varepsilon}_{2 t} / \hat{h}_{2 t}^{1 / 2}-1$, where $\hat{\varepsilon}_{1 t}$ and $\hat{\varepsilon}_{2 t}$ are extracted from univariate $\operatorname{AR}(1)$ $\operatorname{TARCH}(1,1,1)$ processes corresponding to the two time series $R_{i}(t)$ and $R_{j}(t)$, Hong (2001) proposed the test statistic, $S_{1}$ to test the unidirectional Granger causality-in-mean between the two series:

$S_{1}=\left[T \sum_{j=1}^{T-1} k^{2}(j / L) \hat{\rho}_{u v}^{2}(j)-C_{1 T}\right] /\left[2 D_{1 T}\right]^{1 / 2}$

Here, $L$ is the lag function number under some specifications of the kernel function, $\mathrm{k}($.$) that assigns weights to the cross-correlation$ coefficients, $\hat{\rho}_{u v}(j)$, and $C_{1 T}$ and $D_{1 T}$ are functions of $k($.$) . Both S_{1}$ and $S_{2}$ are $\mathrm{N}(0,1)$ under the null hypothesis of no Granger causality in mean. Current study selects the number of lags as $L=15$ (i.e., up to three business weeks). The kernel function $k(j / L)$ is set to the Daniel kernel and it is to be noted that the results corresponding to other continuous function kernels are very similar.

Volatility spillover implies that a market shock not only increases the volatility of its own market, but also increases the volatility in another market as well. According to Clive W. J. Granger and John (1986), Cheung and $\mathrm{Ng}$ (1996), and Hong (2001), the causality-in-variance between $R_{i}(t)$ and $R_{j}(t)$ is tested by testing the null hypothesis of no causality-in-variance from market $j$ to market $i$ in equation (4).

$E\left[\left(M_{i}(t)-m_{i}(t)\right)^{2} \mid \Phi_{i}(t-1)\right]=E\left[\left(M_{i}(t)-m_{i}(t)\right)^{2} \mid \Phi(t-1)\right]$ 
Here, $m_{i}(t)$ is the mean of $R_{i}(t)$ conditional on $\Phi(\mathrm{t}-1)$. In testing the hypotheses in (4), the Hong's (2001) test of Granger causality in variance considers the squares of the centred standard residuals, $\hat{u}_{t}=\hat{\varepsilon}_{1 t}^{2} / \hat{h}_{1 t}-1$, $\hat{v}_{t}=\hat{\varepsilon}_{2 t}^{2} / \hat{h}_{2 t}-1$. Hong (2001) shows that similar asymptotic theories that apply to the test statistic in (3) can also be applied in testing for the Granger causality in variance as well. As a result, this test calculates the test statistics, $S_{1}$ under the null hypothesis of no Granger causality-in-variance using a similar approach.

In order to test the causality-in-downside (-upside) risk, it has been considered the co-movements between the left (right) tails of the two distributions of the return series $R_{i}(t)$ and $R_{j}(t)$ corresponding to the market sectors $i$ and $j$. According to Hong et al. (2009), the hypothesis of no causality-in-extreme downside risk in (5) was tested.

$\operatorname{Pr}\left[R_{i}(t)<\operatorname{VaRd}_{i}(t) \mid \Phi_{i}(t-1)\right]=\operatorname{Pr}\left[R_{i}(t)<\operatorname{VaRd}_{i}(t) \mid \Phi(t-1)\right]$

Here $\operatorname{VaRd}_{i}(t)$ and $\operatorname{VaRd}_{j}(t)$ are the $\alpha$-level value-at-risk (VaR) of the low returns in markets $i$ and $j$ respectively conditional on $\Phi(t-1)$. Let $Z d_{i}(t) \equiv \mathbf{1}\left[R_{i}(t)<\operatorname{VaRd}_{i}(t)\right]$ and $Z d_{j}(t) \equiv \mathbf{1}\left[R_{j}(t)<\operatorname{VaRd}_{j}(t)\right]$. Using the sample cross correlation function between the two indicator series, $Z d_{i}$ and $Z d_{j}$, Hong et al. (2009) propose test statistic similar to (3) to test unidirectional Granger causality in VaR. Rejection of the no causality-indownside risk hypothesis in (5) implies that the past information related to downside risk events in market $j$ would cause downside market risks in returns of market $i$. Estimation of the $\alpha$-level value-at-risk (VaR) corresponds conditional autoregressive value-at-risk methodology proposed by Engle and Manganelli (2004). ${ }^{2}$

Moreover, a rise in energy prices may impact other markets as energy products are used as inputs in almost all the industries and also due

\footnotetext{
${ }^{2}$ Engle and Manganelli (2004) use an autoregressive quantile regression approach to estimate $\mathrm{VaR}$ series corresponding to a return series. They introduce four model specifications and among them, the author uses the asymmetric slope specification in this paper. See Engle and Manganelli (2004) for more details.
} 
to the speculation by financial investors. The author tests this impact using the causality in upside risk hypothesis defined in (6) using a similar procedure under the null hypothesis of no causality-in-extreme upside risk.

$\operatorname{Pr}\left[R_{i}(t)>\operatorname{VaRu} u_{i}(t) \mid \Phi_{i}(t-1)\right]=\operatorname{Pr}\left[R_{i}(t)>\operatorname{VaRu} u_{i}(t) \mid \Phi(t-1)\right]$

In order to compute the test statistic in Hong et al. (2009) causality test, I let $Z u_{i}(t) \equiv \mathbf{1}\left[R_{i}(t)>V a R u_{i}(t)\right]$ and $Z u_{j}(t) \equiv \mathbf{1}\left[R_{j}(t)>V a R u_{j}(t)\right]$. The $\alpha$-level value-at-risk ( $\mathrm{VaR})$ was estimted with corresponding to upside risks by modifying conditional autoregressive value at risk in Engle and Manganelli (2004) by using the right tail quantiles instead of the left tail quantiles.

\section{Impulse Response Analysis}

This section examines the extent to which a current shock to one market affects another market during the 10 days since the shock. The difference between the Granger causality analysis in section 2.2 and the impulse response analysis is that the Granger causality analysis examines the spillover effects from events that have already occurred in the past (expost), while the impulse response analysis considers the potential spillover of information (ex-ante) due to an immediate shock in a market. Here, the study employs the generalized impulse response function developed by Pesaran and Shin (1998) as follows.

Let us consider a stationary $K$-variable $\operatorname{VAR}(p)$ specification for stock market returns in $K$ countries ${ }^{3}$ such that $R(t)=$ $\left\{R_{1}(t), R_{2}(t), \ldots, R_{K}(t)\right\}$, and

$R(t)=\sum_{l=1}^{p} \varphi_{l} R(t-l)+\varepsilon(t)$

where, $\varepsilon(t) \sim(0, h)$ is a vector of independent and identically distributed disturbances. Assuming covariance stationarity in the $K \times K$ dimensional diagonal matrices $\varphi_{l}$, the specification in (7) can be transformed into the moving average specification as in equation (8).

\footnotetext{
${ }^{3}$ In this paper, $K=2$ as the study considers two countries at a time.
} 
$M(t)=\sum_{l=0}^{\infty} A_{l} \varepsilon(t-l)$

Here, the $K \times K$ dimensional coefficient matrices corresponding to each lag $l$ with elements $A_{l}$ obey the recursion $A_{l}=\varphi_{1}, A_{, l-1}+\varphi_{2} A_{l-2}+\cdots+$ $\varphi_{p} A_{l-p}$ with $A_{0}=I$, and $A_{l}=0_{K \times K}$ for $l<0$. Pesaran and Shin (1998) introduce the generalized impulse response function for $n$-periods ahead as $h_{K \times K}^{-1 / 2} A_{n} H e_{i}$ where $H$ is the $(K \times K)$ error covariance matrix of the $\operatorname{VAR}(p)$ process with diagonal elements $h_{i}, A_{n}$ is an $(K \times K)$ diagonal matrix of coefficients $A_{i, n}$, and $e_{i}$ is a selection vector such that $e_{i}=1$ for the $i^{t h}$ market $(i=1,2, \ldots K)$ and 0 otherwise. Thus the $n$ periods ahead information spillover (i.e., the scaled generalized impulse response function, $I R F_{i j}$ from market $i$ to market $j$ ) can be represented by equation (9).

$I R F_{i j}=h_{i}^{-1 / 2} e_{j}^{\prime} A_{n} H e_{i}$

Using the equation (9), I construct the impulse response plots for each market sector using a VAR(2) specifications ${ }^{4}$ to illustrate the potential impacts of shocks on other Asian stock markets to the Sri Lankan stock market and vice versa.

\section{Data and Results}

The study use daily data of value-weighted equity market indices from each country covering the period from 01 January 2000 to 31 January 2012. I use the Nifty index of India, Shanghai stock index (SSE) of China, KSE100 index of Pakistan, MSCI index of Singapore (MSCISG), SLCI index of Malaysia, Hang Seng index of Hong Kong, KOSPI index of Korea, and Nikkei 225 index of Japan. In order to represent the Sri Lankan stock market, this study employed the all share price index of CSE (ASPI). As a robustness check, the analysis using MSCI Sri Lankan index and compare with the results of ASPI was repeated. Under the MSCI taxonomy, Hong Kong, Japan and Singapore are categorized as 'developed' markets, with the remainder classified as 'emerging' markets. Data were retrieved from Bloomberg for daily index values and calculate daily log return values. Figure 1 illustrates the cumulative returns which are analogous to the

\footnotetext{
${ }^{4}$ The author limits the model for $\operatorname{VAR}(2)$ (i.e., $p=2$ ) as the inclusion of further lags does not make a significant contribution over the loss of degrees of freedom.
} 
movement of index values. The first impression is that all the indices follow a similar movement. It can be noticed that all the indices declined after mid2007 which can be attributable to the global financial crisis (GFC). Overall, all the stock price indices are trending upwards during the time. Moreover, Table 1 presents descriptive statistics for each return series for the period 2000 to 2012. Sample means, standard deviations, skewness, kurtosis, along with the test statistics for ADF test for unit root, Ljung-Box test for serial autocorrelations, and Engle's ARCH Test for heteroscedasticity. Table 1 also presents results for Engle and Granger (1987) tests for cointegration between the Sri Lankan stock market and the other Asian stock markets.

It is evident from Table 1 that the average returns are positive in general except for Japan. This indicates that the long-run profitability exists in these markets due to increasing trends especially among emerging markets than the developed markets. Relatively high volatility can be observed in Indian and Korean stock markets compared with the other markets. China, Singapore, and Sri Lanka indicate positive skewness while all the other markets indicate negative skewness. Hence, most of these markets are exposed to negative shocks than positive shocks. On the other hand, Sri Lankan market indicate high skewness values ( 0.96 for ASPI and 1.73 for MSCISL) depicting the possibility of high positive shocks. Second largest skewness value is recorded from Singapore (0.87). Furthermore, all the returns series are leptokurtic, having significantly fatter tails and higher peaks which can be seen from the kurtosis statistics that are greater than three. In can be noted that the Sri Lankan market shows extremely high kurtosis values (35.75 for ASPI and 39.86 for MSCISL) compared to other markets. ADF tests justify that all return series are significantly stationary while Ljung-Box tests justify the serial autocorrelations except in China and Singapore. Existence of serial autocorrelations may lead to market inefficiencies due to potential predictability of future returns. Significance of heteroscedasticity is also evident from the Engle's ARCH test. Therefore, the information content in volatility dynamics is also justified. 
Figure 1: Cumulative returns of market indices
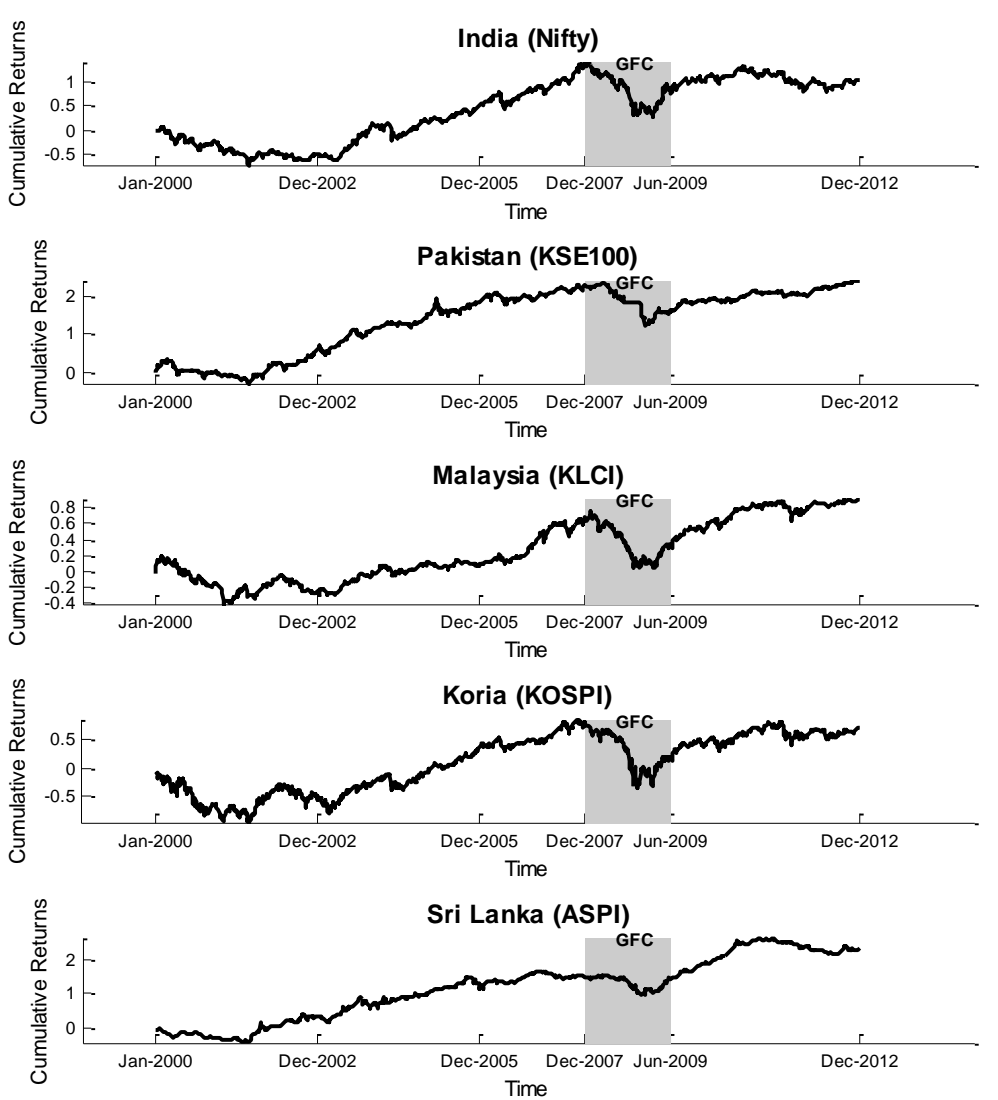

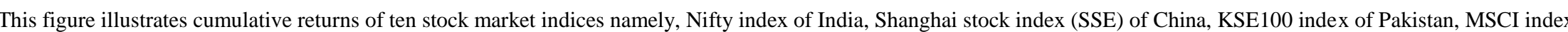

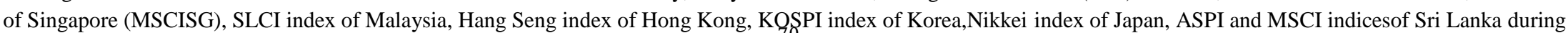
01-01-2000 and 31-12-2012. The shaded area represents the GFC from 2007/12/01 to 2009/6/3
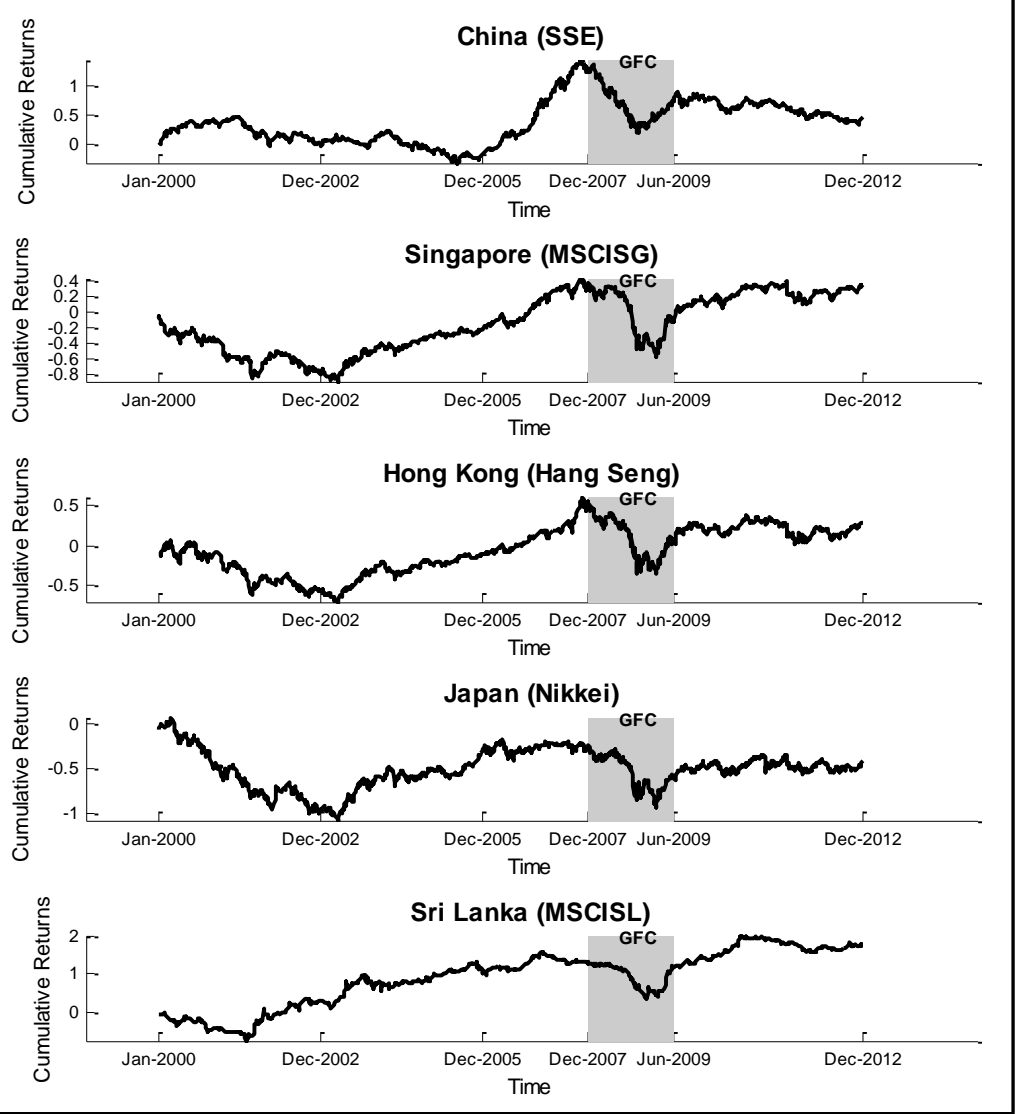
Table 1: Summary statistics and correlations of daily returns for ten stock market indices

\section{Panel A: Descriptive statistics and other fundamentals of returns}

\begin{tabular}{|c|c|c|c|c|c|c|c|c|c|c|}
\hline & $\begin{array}{l}\text { India } \\
\text { (Nifty) }\end{array}$ & $\begin{array}{l}\text { China } \\
\text { (SSE) }\end{array}$ & $\begin{array}{c}\text { Pakistan } \\
\text { (KSE100) }\end{array}$ & $\begin{array}{l}\text { Singapore } \\
\text { (MSCISG) }\end{array}$ & $\begin{array}{c}\text { Malaysia } \\
\text { (KLCI) }\end{array}$ & $\begin{array}{c}\text { Hong Kong } \\
\text { (Hang Seng) }\end{array}$ & $\begin{array}{c}\text { Korea } \\
\text { (KOSPI) }\end{array}$ & $\begin{array}{c}\text { Japan } \\
\text { (Nikkei) }\end{array}$ & $\begin{array}{c}\text { Sri Lanka } \\
\text { (ASPI) }\end{array}$ & $\begin{array}{l}\text { Sri Lanka } \\
\text { (MSCISL) }\end{array}$ \\
\hline Mean & 0.0004 & 0.0002 & 0.0010 & 0.0001 & 0.0004 & 0.0001 & 0.0003 & -0.0002 & 0.0009 & 0.0007 \\
\hline Stdev & 0.0214 & 0.0186 & 0.0174 & 0.0175 & 0.0125 & 0.0174 & 0.0259 & 0.0181 & 0.0155 & 0.0198 \\
\hline Skewness & -0.1341 & 0.2772 & -0.1477 & 0.8711 & -0.3854 & -0.0344 & -0.5217 & -0.4121 & 0.9603 & 1.7320 \\
\hline Kurtosis & 11.2809 & 7.1148 & 7.4872 & 25.5573 & 11.8445 & 11.7922 & 13.7162 & 9.2042 & 35.7530 & 39.8633 \\
\hline Sample Size & 2409 & 2409 & 2409 & 2409 & 2409 & 2409 & 2409 & 2409 & 2409 & 2409 \\
\hline ADF Test & $-19.9171 * * *$ & $-20.9051 * * *$ & $-17.8543^{* * * *}$ & $-20.5366^{* * *}$ & $-19.4621 * * *$ & $-21.1281 * * *$ & $-20.5188^{* * *}$ & $-20.9239 * * *$ & $-18.2264 * * *$ & $-18.6552 * * *$ \\
\hline LBQ Test & $16.7585^{* * * *}$ & 8.996 & $39.9743 * * *$ & 7.7386 & $31.9841 * * *$ & $20.3692 * * *$ & $21.4481 * * *$ & $15.2339 * * *$ & $56.2545^{* * *}$ & $71.2702 * * *$ \\
\hline ARCH Test & 125.0554 **** & $91.7099 * * *$ & 266.7803 **** & $28.0766^{* * * *}$ & $67.4301 * * *$ & $303.8499 * * *$ & $245.9086^{* * * *}$ & $374.0390 * * * *$ & $54.5218^{* * * *}$ & $52.8224 * * *$ \\
\hline $\begin{array}{c}\text { Cointegration } \\
\text { with ASPI }\end{array}$ & -2.1874 & -1.3677 & -1.9059 & -3.0287 & -2.0884 & -2.4638 & $-3.5445^{* *}$ & -3.0445 & & \\
\hline with MSCISL & -2.109 & -1.3828 & -2.6361 & -2.7518 & -1.7466 & -2.3146 & $-3.6573 * *$ & $-3.0607 *$ & -1.896 & \\
\hline
\end{tabular}

\section{Panel B: Correlations}

\begin{tabular}{|c|c|c|c|c|c|c|c|c|c|c|}
\hline India & 1 & & & & & & & & & \\
\hline China & $0.2270 * * *$ & 1 & & & & & & & & \\
\hline Pakistan & $0.1105 * * *$ & $0.0624 * * *$ & 1 & & & & & & & \\
\hline Singapore & $0.5800 * * *$ & $0.2426 * * *$ & $0.1071 * * *$ & 1 & & & & & & \\
\hline Malaysia & $0.4269 * * *$ & $0.2572 * * *$ & $0.1142 * * *$ & $0.5435 * * *$ & 1 & & & & & \\
\hline Hong Kong & $0.4958 * * *$ & $0.3414 * * *$ & 0.1184 *** & 0.6390 *** & $0.5006^{* * * *}$ & 1 & & & & \\
\hline Korea & $0.5104 * * *$ & $0.1994 * * *$ & $0.1137 * * *$ & $0.6360 * * *$ & 0.4633 **** & $0.6494 * * *$ & 1 & & & \\
\hline Japan & $0.3656^{* * *}$ & $0.1914 * * *$ & $0.0914 * * *$ & $0.5059^{* * *}$ & $0.3675^{* * *}$ & $0.6007 * * *$ & $0.5785 * * *$ & 1 & & \\
\hline Sri Lanka-ASPI & $0.1004 * * *$ & 0.0303 & $0.0336^{*}$ & $0.1291 * * *$ & $0.0934 * * *$ & $0.1449 * * *$ & $0.0789 * * *$ & $0.0949 * * *$ & 1 & \\
\hline Sri Lanka_MSCI & $0.1115^{* * *}$ & $0.0376 *$ & 0.0168 & $0.1262 * * *$ & $0.0910^{* * * *}$ & $0.1286^{* * * *}$ & $0.0692 * * *$ & $0.0948^{* * *}$ & $0.8321 * * *$ & 1 \\
\hline
\end{tabular}

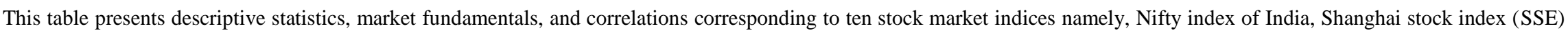

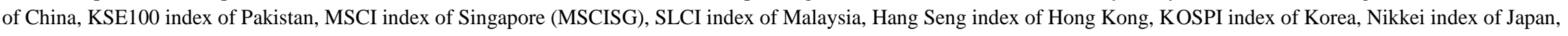

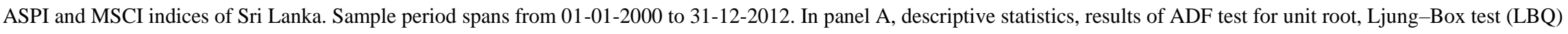

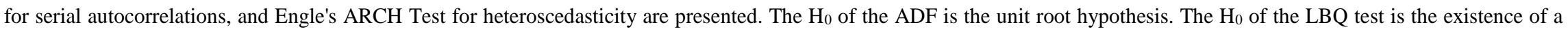

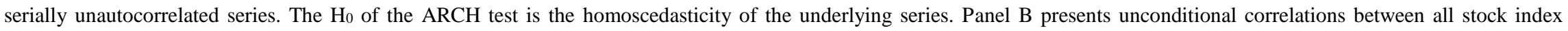
returns. All tests are performed at 5 lags and *** and *** denote significance at the 10, 5 and 1 percent levels, respectively. 


\section{Cointegrations and correlations between stock markets}

Table 1 also presents the results for tests for contegratins between the Sri Lankan stock market and each of other Asian markets. The Korean stock market is significantly cointegrated with the Sri Lankan market which is justified with both ASPI and MSCILK. All the other markets does not indicate integrations with the Sri Lankan stock market. Thus, it is evident that the Sri Lankan stock market does not permanently integrated with the other Asian markets except with Korea. The Korean integration to the Sri Lankan stock market can be expected due to the collaborations between two countries for trading activities in the stock market. Because, trades from Korea at the Sri Lanka stocks exchange have been increasing in the recent past $^{5}$. The implication of the cointegration between Korea and Sri Lanka is that the gains from international diversification for investors with long holding periods are limited between two countries. However, trading partnerships from other Asian countries such as Japan, China and India have no cointegration with the Sri Lankan stock market and opens the gate for the investors to reap arbitrage profits through international diversification of stocks in these countries in long-run. Similar to our results, P. Narayan et al. (2004) also find that the Sri Lankan market is not cointegrated with the south Asian stock markets such as India, Pakistan and Bangladesh though these countries are geographically close to each other.

Panel B in Table 1 presents contemporaneous correlations between index returns of all countries. It is evident that all stock markets are virtually correlated with each other significantly. Correlations among Singapore, Malaysia, Hong Kong and Korea seem to be stronger than other correlations. This result favours the view that geographically and economically closer markets exhibit higher correlation and more short-run comovements among them. Similar results can be found from Madaleno and Pinho (2012). However, Sri Lankan stock market is not active as other stock markets to be correlated in daily basis. Though significant correlations exists between Sri Lanka and other Asian markets, they are relatively weak. This finding is consistent with Elyasiani et al. (1998) which justifies the weak (mostly insignificant) correlations from the Sri Lankan stock market.

\footnotetext{
${ }^{5}$ http://www.ft.lk/article/465849/Sri-Lanka-South-Korea-trade-rises-by-6-
} 


\section{Granger causality between Sri Lankan and other stock markets}

The lead-lag relationship between stock markets is related to the liquidity of the market, market capitalization and the level of transaction costs which depend, at least partly, on the level of openness and deregulation of the economy (P. Narayan et al., 2004). Table 2 presents the results of Granger causality from other Asian markets to Sri Lankan stock markets and vice versa.

Results in Panel A in Table 2 clearly show that the causality in mean is significant from Pakistan, Malaysia, and Korea up to Sri Lankan market. Both ASPI and MSCISL are affected from the markets implying that the stock market fluctuations in Pakistan, Malaysia, and Korea up to past three weeks may cause the stock market movements in Sri Lanka. However, causality in mean from the Sri Lankan market to other Asian markets is not significant indicating that the stock market fluctuations in Sri Lanka has no impact on the markets on their levels. However, Panel B demonstrate a different picture corresponding to causalities in variance. That is, the volatility arises in Indian and Korean stock markets causes volatility in the Sri Lankan market as far as the ASPI is concerned. Volatility spillover from India is not significant for the MSCISL. Unlike in causality in mean, Pakistan stock market seems to be affected by the Sri Lankan market's volatility. Additionally, results corresponding to MSCISL indicate that Indian, Hong Kong, and Japanese markets absorb volatility in Sri Lankan markets. This implies that the Indian, Hong Kong, and Japanese investors are more focused on the MSCISL index than the ASPI. Moreover, Panel C in Table 2 justify that an extreme downside movement in Chinese stock market returns Granger causes the Sri Lankan stock market. However, this impact is not significant for the MSCISL. Apart from the extreme downside risk impact of China, there are no significant downside risk spillovers at 5 percentlevel. Also, according to Panel D in Table 2, upside risk spollovers are also not significant at 5 percent level. This implies that extreme high stock returns in one country does not cause on other countries' stock returns within the Asian region. 
Table 2: Granger causality test results

\begin{tabular}{|c|c|c|c|c|}
\hline & $\begin{array}{c}\text { To } \\
\text { ASPI } \\
\end{array}$ & $\begin{array}{l}\text { From } \\
\text { ASPI } \\
\end{array}$ & $\begin{array}{c}\text { To } \\
\text { MSCISL }\end{array}$ & $\begin{array}{c}\text { From } \\
\text { MSCISL }\end{array}$ \\
\hline \multicolumn{5}{|c|}{ Panel A: Causality in mean } \\
\hline India (Nifty) & 0.2097 & -0.2320 & 0.2097 & -0.2320 \\
\hline China (SSE) & -1.3219 & -0.5287 & -1.3219 & -0.5287 \\
\hline Pakistan (KSE100) & $1.8997 * *$ & 1.1430 & $1.8997 * *$ & 1.1430 \\
\hline Singapore (MSCISG) & -0.0329 & 0.4194 & -0.0329 & 0.4194 \\
\hline Malaysia (KLCI) & $2.0207 * *$ & 0.4700 & $2.0207 * *$ & 0.4700 \\
\hline Hong Kong (Hang Seng) & -0.1076 & 0.8877 & -0.1076 & 0.8877 \\
\hline Korea (KOSPI) & $2.0265 * *$ & -0.3239 & $2.0265^{* *}$ & -0.3239 \\
\hline Japan (Nikkei) & -0.0585 & 0.0359 & -0.0585 & 0.0359 \\
\hline \multicolumn{5}{|c|}{ Panel B: Causality in variance } \\
\hline India (Nifty) & $12.1370^{* * *}$ & -1.1194 & 0.0858 & $3.1765 * * *$ \\
\hline China (SSE) & -1.3396 & -1.4266 & -0.5270 & $1.3736^{*}$ \\
\hline Pakistan (KSE100) & -1.5035 & $7.4097 * * *$ & -1.1359 & $6.0510 * * *$ \\
\hline Singapore (MSCISG) & -1.0701 & -1.4105 & -1.4648 & 0.3356 \\
\hline Malaysia (KLCI) & -0.1408 & -0.4587 & -1.3478 & -0.0929 \\
\hline Hong Kong (Hang Seng) & 0.5732 & -1.2333 & -1.4744 & $1.6820 * *$ \\
\hline Korea (KOSPI) & $29.6723 * * *$ & -0.6190 & $4.9862 * * *$ & 0.3909 \\
\hline Japan (Nikkei) & -0.3873 & -1.3966 & -1.3675 & $2.2507 * *$ \\
\hline \multicolumn{5}{|c|}{ Panel C: Causality in downside risk } \\
\hline India (Nifty) & -0.4913 & -0.2472 & -0.3766 & 0.8690 \\
\hline China (SSE) & $2.4280 * * *$ & -0.6919 & -0.1047 & -0.5081 \\
\hline Pakistan (KSE100) & -1.2747 & 1.0474 & 0.8092 & $1.3252 *$ \\
\hline Singapore (MSCISG) & -1.2064 & 0.2003 & -1.3621 & 0.5098 \\
\hline Malaysia (KLCI) & 0.5685 & $1.5669 *$ & 0.6744 & 0.2459 \\
\hline Hong Kong (Hang Seng) & -0.3224 & -0.0855 & -0.5500 & 0.9235 \\
\hline Korea (KOSPI) & 0.4716 & -0.1184 & 0.7158 & 0.4512 \\
\hline Japan (Nikkei) & 0.1027 & -0.4623 & 0.1179 & -0.9237 \\
\hline \multicolumn{5}{|c|}{ Panel D: Causality in upside risk } \\
\hline India (Nifty) & 0.0366 & -0.0004 & 0.7003 & 0.5145 \\
\hline China (SSE) & -1.2408 & 1.1829 & -0.9265 & 0.2987 \\
\hline Pakistan (KSE100) & -1.0597 & -0.0562 & 1.0008 & 0.8311 \\
\hline Singapore (MSCISG) & -1.1903 & 0.0897 & -0.9153 & -0.6388 \\
\hline Malaysia (KLCI) & -0.8708 & -0.8284 & -0.0862 & 1.0259 \\
\hline Hong Kong (Hang Seng) & $1.4852^{*}$ & 0.4003 & -0.2539 & -0.8716 \\
\hline Korea (KOSPI) & 0.2881 & 0.1455 & 0.6867 & -0.4361 \\
\hline Japan (Nikkei) & -0.1386 & -0.1943 & -0.9743 & -1.5411 \\
\hline
\end{tabular}

This table presents the results of Granger causality tests between the Sri Lankan stock market and other Asian stock markets using the causality in mean and variance tests due to Hong (2001), and causality in risk tests due to Hong et al. (2009) for the sample period 2000-2012. Daniel kernel with 15 lags is used in all Hong's tests of causality. **** and *** denote significance at the 10, 5 and 1percent levels, respectively. 
As far as previous literature evidences are concerned, Granger causality results corresponding the Sri Lankan market are mixed. For example, Elyasiani et al. (1998) do not find any significant causality with the Sri Lankan market within the region or with the US market. P. Narayan et al. (2004) find that stock prices in Sri Lanka Granger cause stock prices in Pakistan. In contrast, De Gooijer and Sivarajasingham (2008) do not find any causal relationships in means from Sri Lanka to other markets. However, Pakistan is not included in their study. Unlike these existing literature, this paper extends the analysis to volatility and risk spillovers where previous literature related to Sri Lankan markets focuses only on mean spillovers. Also, our sample time period spans from 2000-2012 which includes the GFC in 2008 and the post-war period in Sri Lanka. Therefore, significant causalities that demonstrate in this paper are not surprising.

\section{Impulse Response Functions}

Further to cointegration, correlation, and Granger causality tests, the author use impulse response functions to investigate the interaction between the Sri Lankan stock market and the other Asian stock markets. The specific purpose of using impulse response functions is to investigate the potential impact of a current shock to one market on the following days of other markets. This function enables characterization of the dynamic interactions among stock markets and allows us to observe the speed of adjustment of index returns in the system. Figure 2 illustrates the impulse responses due to one standard deviation shocks on other Asian markets to the following ten days of the Sri Lankan market. Impulse responses for both ASPI and MSCISL indices are computed along with 90percent simulated confidence intervals. Thus, a confidence band staying away from the zero infers a significance impulse response in the Sri Lankan stock market due to a shock on other markets. 
Figure 2: Generalized impulse responses

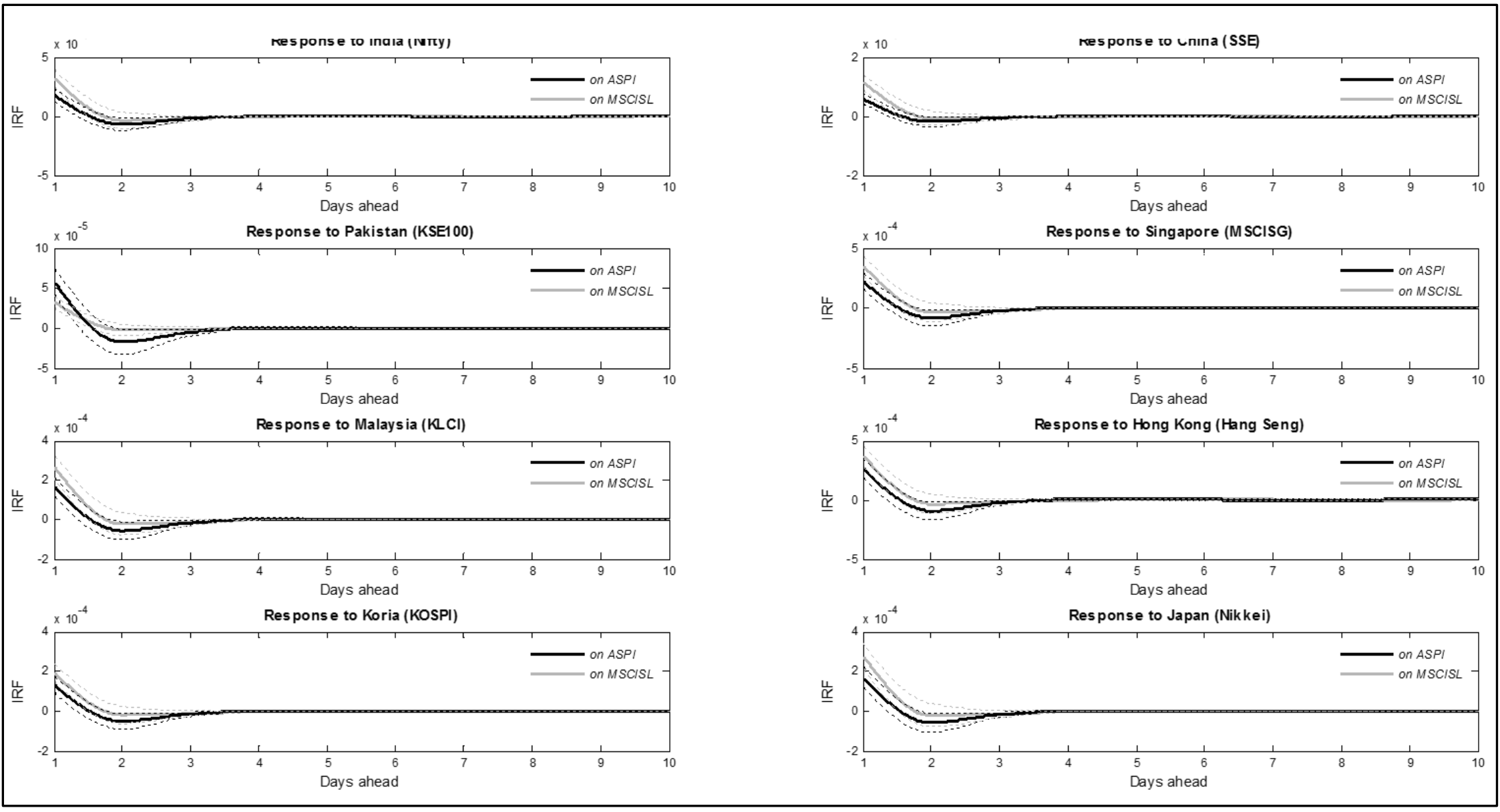

This figure illustrates generalized impulse response functions due to a chock on each Asian stock market on the Sri Lankan stock market over the period from 1st January 2000 to 31st December 2012. The responses corresponding to ASPI and MSCISL respectively are plotted in each graph in black and grey colours. Dotted lines represent 90percent simulated confidence bands. 
Figure 3 clearly demonstrates that the Sri Lankan stock market is sensitive to current shocks on other Asian markets only for the following day. The magnitudes of the response in two Sri Lankan stock market indices (ASPI, MSCISL) are close to each other. Moreover, both Sri Lankan stock indices reacts positively to all other Asian stock market shocks. This result contradicts the previous finding in Elyasiani et al. (1998) corresponding to the response of the Sri Lankan stock market due to other market shocks where Elyasiani et al. (1998) documents that the Sri Lankan stock market does not significantly response to other Asian market shocks during 1989 to 1994. However, P. Narayan et al. (2004) document that shocks to stock prices in India, and Pakistan during the sample period from 1995 to 2001 have a positive effect on stock prices in Sri Lanka which is consistent with ours. Thus, it is evident that the sensitivity in the Sri Lankan stock market over the movements in neighboring markets has been changed after 1994. This may be due to the implementation of the automated electronic clearing and settlement Central Depository System in 1991 which causes the trading activities more transparent and dynamic.

\section{Conclusion}

This paper addresses three major research questions related to the Sri Lankan stock market; 1) Does the Sri Lankan stock market integrate with other Asian stock markets? 2) Are there information spillovers from other Asian markets on the Sri Lankan stock market? 3) Is the information in the Sri Lankan stock market spilled over to other Asian stock markets? Market integration is examined by the cointegration of market indices and correlations of index returns between the Sri Lankan stock market and other Asian stock markets namely, India, China, Pakistan, Singapore, Malaysia, Hong Kong, Korea, and Japan. The autor use daily data from $01^{\text {st }}$ January 2000 to $31^{\text {st }}$ December 2012. Findings reveal that the Sri Lankan stock market is cointegrated with Korean stock market but not with others. Contemporaneous correlations are significant between Sri Lanka and other Asian countries such as India, Singapore, Malaysia, Hong Kong, Korea, and Japan. Pakistan, Malaysian, and Korean stock markets Granger causes in mean to the Sri Lankan stock market while India and Korea Granger causes in variance. Extreme downside risks in Chinese stock market also Granger causes the Sri Lankan stock market. Impulse response analysis provides evidence for the following day's 
impact on the Sri Lankan stock market due a current shock on other Asian stock markets. Our results are mostly consistent with the recent literature such as P. Narayan et al. (2004) but not with the former literature such as Elyasiani et al. (1998). It is well known that, at least at the beginning of the 1990s, South Asian markets have undergone rapid market liberalization, which has opened up the region to higher investment and trade flows. Moreover, the post war era in Sri Lanka after 2009 assumes a safe market condition for the investments. Therefore, our findings have to be interesting to the investors of the Sri Lankan stock market.

\section{References}

Cheung, Y. W., \& Ng, L. K. (1996). A causality-in-variance test and its application to financial market prices. Journal of Econometrics, 72(1-2), 33-48.

CSE. (2014). Colombo stock exchange - Investing in shares - A basic guide.

De Gooijer, J. G., \& Sivarajasingham, S. (2008). Parametric and nonparametric Granger causality testing: Linkages between international stock markets. Physica A: Statistical Mechanics and its Applications, 387(11), 2547-2560.

Elyasiani, E., Perera, P., \& Puri, T. N. (1998). Interdependence and dynamic linkages between stock markets of Sri Lanka and its trading partners. Journal of Multinational Financial Management, 8(1), 89-101.

Engle, R. F., \& Granger, C. W. J. (1987). Cointegration and error correction - Representation, estimation, and testing. Econometrica, 55(2), 251-276.

Engle, R. F., \& Manganelli, S. (2004). CAViaR: Conditional autoregressive value at risk by regression quantiles. Journal of Business \& Economic Statistics, 22(4), 367-381.

Granger, C. W. J. (1980). Testing for causality - Apersonal viewpoint. Journal of Economic Dynamics \& Control, 2(4), 329-352.

Granger, C. W. J., \& John, W. (1986). Wholesale and retail prices : Bivariate time-series modeling with forecastable error variances.Model reliability. Cambridge, Mass. MIT Press, p. 1-17.

Hong, Y. M. (2001). A test for volatility spillover with application to exchange rates. Journal of Econometrics, 103(1-2), 183-224.

Hong, Y. M., Liu, Y. H., \& Wang, S. Y. (2009). Granger causality in risk and detection of extreme risk spillover between financial markets. Journal of Econometrics, 150(2), 271-287. 
Joshi, P. (2011). Return and volatility spillovers among Asian stock markets. SAGE Open. DOI: 10.1177/2158244011413474

Li, H., \& Majerowska, E. (2008). Testing stock market linkages for Poland and Hungary: A multivariate GARCH approach. Research in International Business and Finance, 22(3), 247-266.

Madaleno, M., \& Pinho, C. (2012). International stock market indices comovements: a new look. International Journal of Finance \& Economics, 17(1), 89-102.

Narayan, P., Smyth, R., \& Nandha, M. (2004). Interdependence and dynamic linkages between the emerging stock markets of South Asia. Accounting \& Finance, 44(3), 419-439.

Narayan, S. (2015). Are Asian stock market returns predictable? Emerging Markets Finance and Trade, 51(5), 867-878.

Pesaran, H. H., \& Shin, Y. (1998). Generalized impulse response analysis in linear multivariate models. Economics Letters, 58(1), 17-29.

Phillips, P. C. B., \& Ouliaris, S. (1990). Asymptotic properties of residual based tests for cointegration. Econometrica, 58(1), 165-193.

Worthington, A., \& Higgs, H. (2004). Transmission of equity returns and volatility in Asian developed and emerging markets: A multivariate GARCH analysis. International Journal of Finance \& Economics, 9(1), 71-80.

Yang, J., Hsiao, C., Li, Q., \& Wang, Z. (2006). The emerging market crisis and stock market linkages: Further evidence. Journal of Applied Econometrics, 21(6), 727-744. 